\title{
Detection of quantitative trait loci and putative causal variants affecting somatic cell score in dairy sheep by using a 50K SNP chip and whole-genome sequencing
}

\author{
B. Gutiérrez-Gil, ${ }^{1,2}$ C. Esteban-Blanco, ${ }^{1}$ A. Suarez-Vega, and J. J. Arranz \\ Departamento de Producción Animal, Facultad de Veterinaria, Universidad de León, Campus de Vegazana s/n, León 24071, Spain
}

\begin{abstract}
This study presents a scan of the ovine genome to identify quantitative trait loci (QTL) influencing the somatic cell score (SCS), a classical indicator of subclinical mastitis in sheep, and a subsequent highresolution analysis of one of the identified QTL regions based on the analysis of whole-genome sequence data sets. A half-sib commercial population of Churra sheep genotyped with a 50K SNP chip was analyzed using linkage analysis (LA) and combined linkage and linkage disequilibrium analysis (LDLA). By LA, 2 5\% chromosome-wide significant QTL on OAR5 and OAR25 and one $5 \%$ genome-wide significant QTL on ovine chromosome 20 (OAR20) were detected, whereas 22 significant associations were identified by LDLA. Two of the associations detected by LDLA replicated LAdetected effects (OAR20, OAR25). We compared the detected associations with previously reported QTL in sheep and cattle, and functional candidate genes were identified within the estimated confidence intervals. We then performed a high-resolution analysis of the OAR20 QTL region, the most significant QTL region identified by LA that replicated a QTL previously described in Churra sheep for SCS using microsatellite markers. For that, 2 segregating trios of 2 segregating families for the OAR20 QTL (each including the $Q q$ sire and 2 daughters, $Q Q$ and $q q$ ) were selected for wholegenome sequencing. The bioinformatic analysis of the 6 sequenced samples performed across the genomic interval considered $(14.2-41.7 \mathrm{Mb})$ identified a total of 227,030 variants commonly identified by 2 independent software packages. For the 3 different concordance tests considered, due to discrepancies regarding the QTL peak in the segregating families, the list of mutations
\end{abstract}

Received March 12, 2018.

Accepted June 21, 2018.

${ }^{1}$ These two authors equally contributed to this work.

${ }^{2}$ Corresponding author: beatriz.gutierrez@unileon.es concordant with the QTL segregating pattern was processed to identify the variants identified in immunerelated genes that show a moderate/high impact on the encoded protein function. Among a list of 85 missense variants concordant with the QTL segregation pattern that were within candidate immune-related genes, 13 variants distributed across 7 genes [PKHD1, NOTCH4, AGER, ENSOARG00000009395 (HLA-C, Homo sapiens), ENSOARG00000015002 (HLA-B, H. sapiens), MOG, and ENSOARG00000018075 (BoLA, Bos taurus, orthologous to human $H L A$-A] were predicted to cause deleterious effects on protein function. Future studies should assess the possible associations of the candidate variants identified herein in commercial populations with indicator traits of udder inflammation (SCS, clinical mastitis).

Key words: mastitis, quantitative trait loci, single nucleotide polymorphism-chip, genomic sequencing, genetic marker

\section{INTRODUCTION}

In dairy species, the SCC of milk represents a predictive marker of the udder health and is widely used for evaluating milk quality. It also influences milk prices. An increased SCC is either the consequence of an inflammatory process due to the presence of an IMI or, under nonpathological conditions, due to physiological processes such as estrus or an advanced stage of lactation (Raynal-Ljutovac et al., 2007).

Subclinical mastitis constitutes one of the major problems influencing total productivity in dairy sheep. Therefore, resistance/susceptibility to this disease can be considered an important functional trait for the milk production sector. Because SCC provides a measurement of the level of defensive cells that migrate from blood to mammary gland as a response to infection (Gonzalo and Gaudioso, 1985), log-transformed SCC, known as the SCS, can be used as an indicator trait to achieve genetic improvement for mastitis resistance (Shook and Schutz, 1994). Although direct selection 
for mastitis resistance has been implemented in dairy cattle for over $35 \mathrm{yr}$ in Nordic countries (Østerås et al., 2007) and more recently in France (GovignonGion et al., 2016) and Canada (Jamrozik et al., 2013), most countries breed for mastitis resistance indirectly through SCS (Miglior et al., 2005). In dairy sheep, the SCS is considered a functional indicator trait of subclinical mastitis and is one of the factors influencing the price that farmers receive for the milk. In dairy sheep, reported heritability estimates of SCS range between 0.06 and 0.18 (Othmane et al., 2002; Rupp et al., 2003; Legarra and Ugarte, 2005). The SCS is included as a selection target in the breeding scheme of the French Lacaune breed (Barillet et al., 2006). In Churra sheep, although SCS is routinely recorded through the official recording control, the low number of rams under genetic evaluation makes consideration of this trait unfeasible when calculating the selection index. Indirect selection for subclinical mastitis resistance is performed in Churra sheep through the inclusion of udder morphology traits as selection objectives (de la Fuente et al., 1996), with the advantage that these traits are more heritable than SCS. The efficiency of this indirect selection to favor stabilization of SCS would be related to the expected genetic correlations between udder traits and mastitis resistance. Hence, in a Lacaune $x$ Sarda backcross population, Casu et al. (2010) reported high genetic correlations between SCS and both udder attachment (measured as degree of suspension of the udder) and udder depth $(-0.42$ and -0.50 , considering a scale of opposite sign for udder depth than in Churra sheep). These estimates suggest that selection for shallow udders, close to the abdominal wall, and udders with higher degree of suspension would be associated with a genetic response toward lower SCS. Although in Churra sheep genetic correlations have not been estimated between udder morphology traits and mastitis resistance, phenotypic correlations reported in this breed between SCS and udder depth and between SCS and teat size are low but positive $(0.13$ and 0.18 respectively), which can be explained by the higher frequency of trauma observed in very deep udders and larger teats than standard teat cups (Fernández et al., 1997).

Nevertheless, taking into account the direct influence of SCS on the price of milk, direct selection on this trait would be of great interest for breeders of Churra dairy sheep. As for other traits showing low heritability, marker- or gene-assisted selection would be a feasible strategy to improve resistance to subclinical mastitis not only in Churra sheep but also in other ovine populations devoted to milk production. Detecting genetic variants directly associated with the SCS trait could be exploited to increase the average resistance level of flocks to subclinical mastitis. Historically, the first at- tempts to identify genes related to this functional trait in dairy sheep populations were genome scans based on microsatellite markers aiming to identify QTL (reviewed by Arranz and Gutiérrez-Gil, 2012). In Churra sheep, an analysis of a half-sib population with 181 markers identified only one chromosome-wide significant QTL for SCS on sheep chromosome 20 (Ovis aries 20; OAR20). However, the low mapping resolution of this scan together with the differences in marker informativeness among the analyzed families limited the ability to identify reliable candidate genes for this QTL effect (Gutiérrez-Gil et al., 2007).

Presently, SNP chips of medium and high density in sheep provide a substantially improved mapping tool for the identification of QTL that directly control traits of economic interest. In addition, animal scientists currently have access to whole-genome sequence-based technologies, which increases their ability to detect and propose mutations as plausible causal mutations or quantitative trait nucleotides (Sellner et al., 2007).

In Churra sheep, a medium-density 50K SNP chip has been used by our research group to map QTL related to milk production traits (García-Gámez et al., 2012) and parasite resistance traits (Atlija et al., 2016). For milk traits, this chip greatly facilitated the identification of the putative causal mutation of a previously described QTL influencing milk protein percentage in Spanish Churra sheep (García-Gámez et al., 2012). In a more recent study, the combination of 50K SNP chip genotyping in a commercial population of French dairy sheep and the analysis of whole-genome sequencing information allowed the identification of the causal mutation of an OAR3 QTL influencing mastitis susceptibility in the SOCS2 gene (Rupp et al., 2015). A custom-made 960-SNP DNA array has been recently used in the Greek Chios breed to confirm previously detected QTL in other sheep breeds and has suggested, for some of the regions, a conserved genetic architecture of mastitis resistance between distinct dairy sheep breeds (Banos et al., 2017).

The objectives of the present study were to (1) perform QTL mapping analyses for the SCS trait using a 50K SNP chip based on linkage (LA) and combined linkage and linkage disequilibrium (LDLA) analyses in the same commercial half-sib population of Churra dairy sheep analyzed for milk production traits by García-Gámez et al. (2012), and (2) exploit the wholegenome sequences of segregating trios to perform a high-resolution study of the genetic variation within the region harboring the most significant QTL detected and assess the polymorphisms showing concordance with the expected QTL genotypes as potential causal variants based on their biological relevance and the physiological effects of the affected gene. 


\section{MATERIALS AND METHODS}

\section{Resource Population, Genotypes, and Phenotypes}

A commercial population of Spanish Churra dairy sheep including 1,598 ewes distributed in 16 half-sib families and the corresponding 16 sires was studied here. The average family size was 99 daughters per ram (ranging from 23 to 266 animals per half-sib family). Test-day SCS (base ${ }_{10}$ logarithmic transformation) records for the ewes of this population were estimated based on the SCC provided by official milking records of the National Churra Breeders' Association (ANCHE). As the response variable for the QTL analysis, we used the yield deviations (YD) for the SCS trait estimated, as previously detailed by García-Gámez et al. (2012), with a multivariate animal repeatability model considering also other milk production traits measured through test-day records (milk yield, protein percentage, fat percentage, protein yield, fat yield). For the YD estimation, the raw phenotypic data were corrected for the environmental effects of herd test day, birth order, age of the ewe at parturition (as a covariate nested within birth order), number of born lambs, number of weeks of milk production of the ewe, and the ewe's permanent environmental effect.

To extract DNA, blood samples for the ewes and semen samples for the sires were collected by the official veterinarians of the breeders' association following standard animal welfare protocols. The whole population was genotyped with the Illumina Ovine SNP50 BeadChip (Illumina Inc., San Diego, CA). An initial control of raw genotypes was performed by applying a GenCall score greater than 0.15. Then, SNP order and genome positions were updated according to version Oar_v3.1 of the ovine genome assembly (http://www .ensembl.org/Ovis_aries/Info/Index) by considering a $1 \mathrm{cM}$ to $1 \mathrm{Mb}$ conversion rate. Only the SNP with known location on the ovine autosomes were considered. Following Anderson et al. (2010), we performed a 2-step quality control of the genotypes: per animal (call rate $>90 \%$ ) and per SNP (call rate $>95 \%$; minor allele frequency $>0.05$; correspondence with Hardy-Weinberg equilibrium: $P>0.00001)$. All the animals under study and a total of 43,613 autosomal SNP passed the quality control filters and were considered in the QTL mapping analysis.

\section{QTL Mapping Analyses}

Genome scans based on a classical LA and a combined LDLA procedure were performed for the SCS trait with the QTLMap software (Filangi et al., 2010), by testing the genome at $0.1 \mathrm{cM}$ step intervals. For the
2 analyses, the half-sib structure of the studied population was indicated in the analysis with the family $=1$ option. A by-default haplotype size of 4 SNP was used for LDLA. Significance thresholds at the chromosomewise significance level ( $P_{c}$-value) were calculated through a total of 1,000 permutations (at $0.1 \mathrm{cM}$ steps) for LA and 1,000 simulations (at $5 \mathrm{cM}$ steps) for LDLA. For both analyses, genome-wise significance thresholds were calculated based on the chromosome-wise $P$-values by applying a Bonferroni correction for the 26 independent chromosomes under analysis $\left(P_{c}\right.$-value $<0.0019$, for a $5 \%$ genome-wise significance level). For the significant QTL that were detected by LA, likelihood ratio test (LRT) values were converted to logarithm odds ratio (LOD) values (Lander and Botstein, 1989), and confidence intervals (CI) for the QTL locations were estimated by the widely used 1-LOD drop-off method. The proportion of phenotypic variance that was explained by the QTL detected by LA was calculated based on the corresponding LOD values using the formula $\sigma_{p}=1-10^{-\frac{2}{n} L O D}$ (Broman and Sen, 2009). In the LDLA, chromosomal regions that involved consecutive significant haplotype associations within a chromosome (allowing gaps no greater than $5 \mathrm{cM}$ ) were grouped as a significant LDLA interval and the remaining ones were considered as isolated significant haplotypes.

\section{Comparison with Previously Reported QTL and Identification of Functional Candidate Genes Within Confidence Intervals}

A systematic search for QTL and associations previously reported in sheep and the extraction of positional candidate genes was performed for the QTL regions detected by LA and LDLA. For each QTL detected, we considered the corresponding target genomic interval (TGI), which was defined as the genomic region based on the sheep reference genome assembly Oar_v3.1 that corresponded to either the estimated CI of the across-family LA analysis and the defined significant LDLA intervals or to a $250 \mathrm{~kb}-$ long interval centered on the significant LDLA-isolated haplotypes detected by LDLA. Once the TGI for each significant association was defined, we extracted the QTL annotated in the SheepQTL database (Hu et al., 2013) in relation to "Health traits" and "Udder" (one of the type traits within the "Exterior traits" category of the database hierarchy). Considering that most gene-mapping studies for mastitis resistance and udder morphology have been performed with dairy cattle populations, we searched for QTL described in the corresponding bovine orthologous regions to the TGI defined in our study based on LA and LDLA. We used Liftover (https://genome.ucsc 
.edu/cgi-bin/hgLiftOver) to define the orthologous coordinates of the TGI in the Bos taurus UMD_3.1 assembly (BTA23:21961453-28742358) and extracted the QTL/associations related to mastitis resistance and udder morphology reported in cattle based on the Cattle database from AnimalQTLdb (Hu et al., 2013).

In addition, the positional candidate genes included within those intervals according to the reference genome were extracted with the BioMart web-based tool based on the Ensembl release 89 (http://www.ensembl .org/biomart/martview/). These positional candidate genes were assessed as putative functional candidate genes in relation to the immune response by performing a survey of a database of 5,029 unique immune-related genes, which was based on the IRIS (1,489 genes; Kelley et al., 2005) and ImmPort (4,677 genes) gene lists, both of which are available at http://www.innatedb .com/redirect.do?go $=$ resourcesGeneLists.

\section{Selection of Target Segregating Trios for Further Study of the Oar20 QTL}

For the most significant QTL detected by LA on OAR20, which was also confirmed by the LDLA results, we selected 2 sires that, according to the within-family analyses, were segregating $(Q q)$ for the OAR20 QTL. For each of these 2 sires, we identified 2 daughters with extreme divergent phenotypes for the SCS trait, in correspondence with the alternative homozygosity genotypes for markers included in the estimated QTL CI. The selection of the daughters was based on the phases obtained for each of the families for the markers included in the QTL within-family CI. For each trio, the sire and the offspring phases were obtained with the out_phases and out_phases_offspring options of QTLMap (Le Roy et al., 2013). To assign the QTL alleles, $Q$ and $q$, to the corresponding paternal phase at the QTL regions, for each of the 2 families considered, the out_pded option of this software was used to estimate the transmission marginal probabilities for all of the animals of the 2 selected families for the QTL peak position in the within-family analysis. By considering the sign of the estimated effect for each sire and the phase of offspring showing extreme divergent inheritance probabilities (close or equal to zero or one) at the target QTL peak position, we could identify the parental haplotype associated with increased or decreased SCS. The haplotype for which a positive effect on the SCS trait was calculated in the regression analyses was denoted as $q$ (increased susceptibility to mastitis), and the haplotype for which a negative effect on the trait was calculated was denoted as $Q$ (increased resistance to mastitis). Based on this, for each selected family, we identified the daughters inheriting the $Q$ and $q$ allele at the corresponding target QTL position and ranked the list based on their individual SCS trait values (YD units). Later, focusing on the region of the within-family QTL peak, we selected homozygous daughters with extreme phenotypes consistent with the QTL effect. Hence, we identified, for each of the 2 selected families, a $Q Q$ daughter showing an extreme low SCS value and a $q q$ daughter showing an extreme high SCS within the family SCS values.

\section{Whole-Genome Sequencing and NGS-Variant Calling}

Six DNA samples, 3 from each selected segregating family, were subjected to whole-genome sequencing by using the paired-end Illumina technology in an Illumina HiSeq 2000 sequencer. The bioinfomatic analysis workflow implemented for these samples was the same as that detailed by Gutiérrez-Gil et al. (2017). Briefly, the raw paired-end reads resulting from sequencing were subjected to quality assessment with FASTQC (http://www.bioinformatics.babraham.ac.uk/projects/ fastqc/). Then, the good quality reads filtered with Trimmomatic (Bolger et al., 2014) were mapped to the ovine reference genome Oar_v3.1 using the BurrowsWheeler Aligner (BWA, mem mapping function; Li and Durbin, 2009). After that, SAMtools3 (Li et al., 2009) and PicardTools (Broad Institute, 2017) were used for diverse manipulations (see Gutiérrez-Gil et al., 2017, for details). Variant calling (SNP and InDEL) was carried out across the whole genome simultaneously for the 6 samples with 2 different software, the Genome Analysis Toolkit (GATK4, version 3.3.0, HaplotypeCaller tool) and Samtools (Li, 2011; mpileup analysis). After discarding low quality variants independently from each resulting VCF file using snpSIFT (Cingolani et al., 2012), an intersect set, containing those variants concordant between GATK and Samtools predictions, was extracted using BCFtools utilities (Li, 2011; Narasimhan et al., 2016) to produce a final VCF file. The reliability of whole-genome sequencing (WGSeq)defined genotypes was determined by comparing with the previously analyzed 50K SNP chip genotypes.

\section{Concordance Tests and Identification of Functional Variant Annotation}

Considering the 6 samples sequenced at the wholegenome level, we performed concordance tests to filter the variants showing genotypic concordance with the considered QTL segregation pattern ( $Q q$ for the 2 sires, and the alternative homozygous genotypes for the daughters showing extreme phenotypes in agreement 


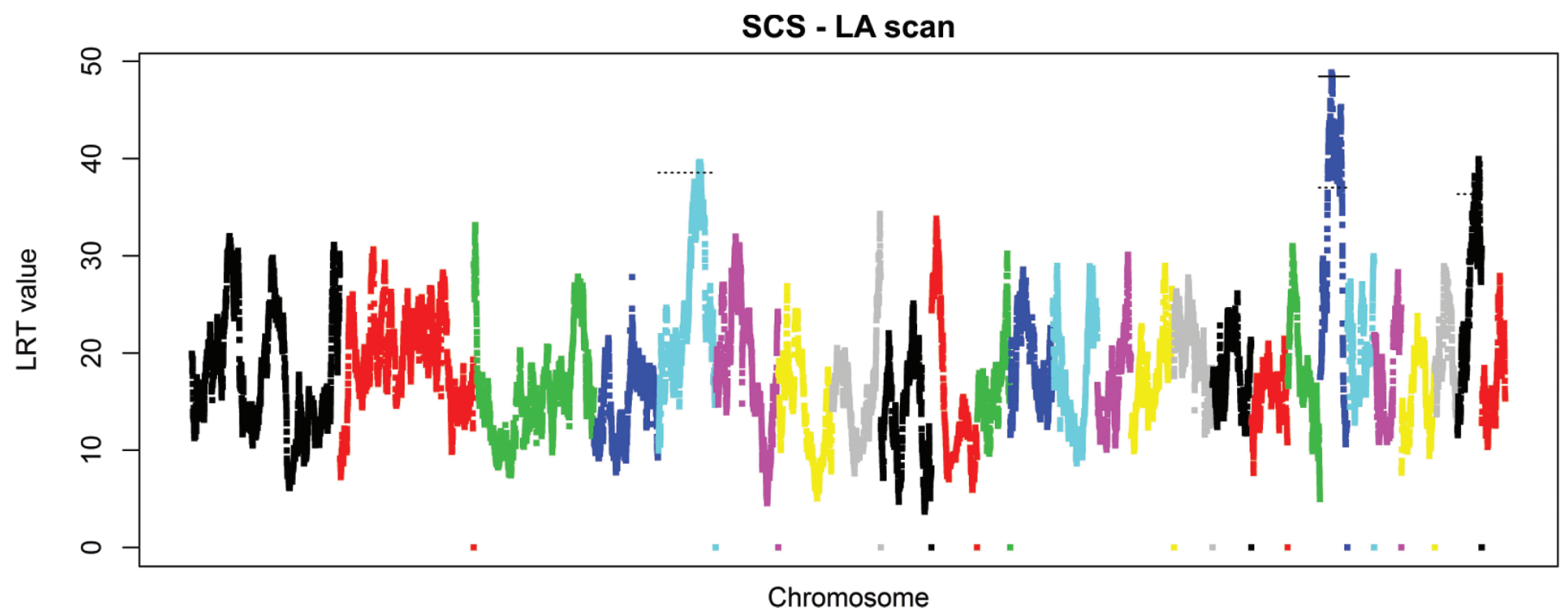

Figure 1. Results of the genome scan based on linkage analysis (LA) performed for the SCS trait studied in the present work. Likelihood ratio test (LRT) values obtained across the 26 ovine autosomes are represented. For the chromosomes (OAR) showing significant results, the dashed horizontal lines (OAR5, OAR20, OAR25) indicate the 5\% chromosome-wise significance threshold, and the solid line (on OAR20) indicates the $5 \%$ genome-wise significance threshold. Color version available online.

with the chromosomal phase inherited from the sire, $Q Q$ or $q q)$.

For the variants satisfying the QTL concordance genotype pattern, for each data set, functional annotation was performed with the Ensembl variant effect predictor (eVEP; McLaren et al., 2010) based on the Ovis_aries build 89 of Ensembl. Based on the functional annotation, we identified the genetic variants (indels and SNP) that were predicted to cause relevant biological effects (stop coding variant, missense variant, or frameshift variant). The classification of the variants as "deleterious" or "tolerated" by the SIFT tool was possible through the eVEP analysis. The known functions of the genes harboring the "deleterious" functional variants were assessed in relation to the immune response by performing a survey with a database of 5,029 immune-related genes considered as reference in this work. This database was based on the IRIS $(1,489$ genes; Kelley et al., 2005) and ImmPort (4,677 genes) gene lists, both of which are available at http://www .innatedb.com/redirect.do?go=resourcesGeneLists.

\section{RESULTS}

\section{QTL Mapping Results}

$\boldsymbol{L} \boldsymbol{A}$ Results. The LA-based genome scan identified a genome-wide significant QTL on OAR20 (5\% genomewise threshold) and 2 chromosome-wide significant QTL on OAR5 (CI: 74.9-81.5 cM) and OAR25 (CI: 38.6-41.7 cM; Figure 1). A summary of the across-fam- ily analysis performed across the 26 ovine autosomes in our resource population is shown in Table 1, which also includes the results of the segregating families identified by the within-family analyses. The CI estimated for the OAR20 QTL (peak: $21.52 \mathrm{cM}$ ) included a 2.9 cM interval (20.9-23.8). For the 3 segregating families identified for this QTL, the magnitude of this QTL effect, expressed in phenotypic standard deviations, was 0.205 (family 1), 0.134 (family 2), and -0.192 (family 6). A single segregating family was identified for each of the chromosome-wide QTL identified on OAR5 and OAR25. For these QTL, the estimated effects were 0.384 and -0.405 , respectively (Table 1 ). The estimated phenotypic variance explained by these QTL was 0.03 for the OAR20 QTL and approximately 0.024 for the 2 other mapped effects.

The results of the across-family analysis of OAR20 (Supplemental Figure S1; https://doi.org/10.3168/jds .2018-14736) show that although the maximum QTL peak was found at $21.52 \mathrm{cM}$, a secondary significant peak was identified at $38 \mathrm{cM}$. This profile is consistent with the results of the within-family analyses in which 2 families showed the maximum LRT and the corresponding estimated CI mapping within the first third of the chromosome and overlapping the across-family CI (family 1 at $18.82 \mathrm{cM}$ and family 2 at $14.8 \mathrm{cM}$ (Table 1; Supplemental Figure S2; https://doi.org/10.3168/ jds.2018-14736), whereas the other segregating family (family 6) showed the maximum LRT value at 38.1 $\mathrm{cM}$, overlapping with the secondary peak identified in the across-family QTL profile. For family 6, significant 


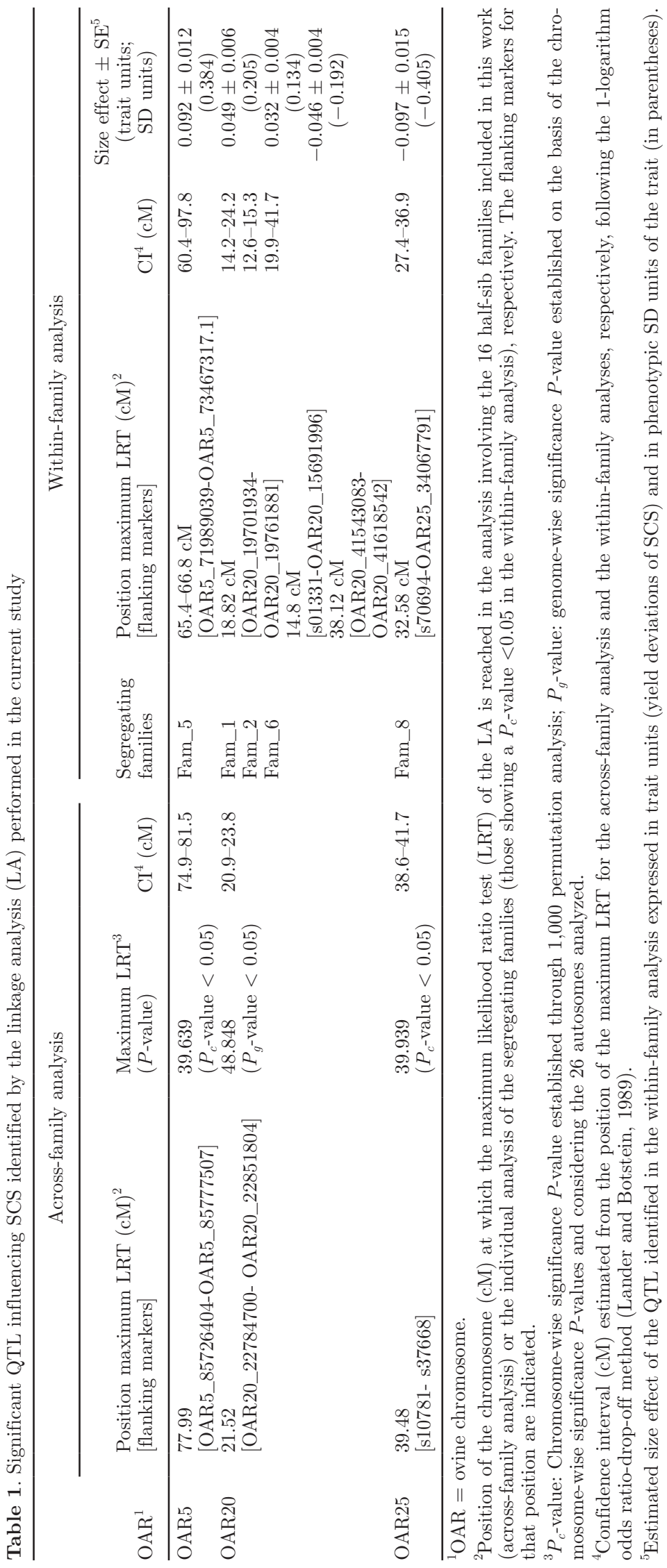


LRT values were detected across most of the second half of the chromosome, resulting in a long estimated CI covering a $21.8 \mathrm{cM}$ interval $(19.9-41.7 \mathrm{cM})$.

LDLA Results. The LDLA scan identified a total of 21 significant QTL (5\% chromosome-wide) distributed across 13 autosomes: OAR1, 2, 3, 8, 11, 13, 14, 17, 18, 19, 20, 22, and 25 (Table 2; Figure 2). Eight of the significant QTL involved consecutive significant haplotypes that defined a significant LDLA interval, whereas the other 13 associations were defined by isolated haplotypes. One of the 2 significant associations located on OAR25 (16.5-16.6 cM) reached the $5 \%$ genome-wide significant threshold. Two 5\% chromosome-wise QTL located on OAR20 (22-28 cM) and OAR25 (32.5-35 $\mathrm{cM}$ ) overlapped with the CI estimated for the significant QTL detected by LA on those chromosomes. As can be seen in Supplemental Figure S1 (https://doi.org/ 10.3168/jds.2018-14736), the LDLA statistical profile observed on OAR20 showed correspondence with that provided by LA, with the most significant region involving the 22 to $28 \mathrm{cM}$ interval. A second significant position was detected by LDLA at the proximal end of the chromosome $(5.4-5.5 \mathrm{cM})$, whereas the $39 \mathrm{cM}$ posi- tion did not exceed the chromosome-wise significance threshold.

\section{Correspondence with Sheep and Cattle QTL and Functional Candidate Genes}

The correspondence between the TGI defined from the identified significant QTL in this work and previously reported QTL/associations annotated in the SheepQTLdb for "Health" and "Udder" traits are presented in Supplemental Table S1 (https://doi.org/10 .3168/jds.2018-14736). The estimated CI for the QTL detected by LA overlapped with 6 QTL annotated for health traits in this database, 3 of which mapped within the OAR20 QTL and 3 of which mapped within the OAR25 QTL. The TGI intervals defined based on the LDLA significant associations collocated with a total of 28 reported health-related QTL/associations, 3 of which were common to the overlapping associations with the LA-defined TGI. Most of these health-related overlapping QTL had been identified in studies focused on parasite resistance, whereas only one QTL underlying mastitis susceptibility was identified, on OAR22

Table 2. Significant QTL influencing SCS identified by the combined linkage disequilibrium and linkage analysis (LDLA) performed in the current study

\begin{tabular}{|c|c|c|c|c|}
\hline $\mathrm{OAR}^{1}$ & $\begin{array}{c}\text { Position of maximum } \\
\text { LDLA significant associations }{ }^{2} \\
\left(P_{c^{-}} \text {value }<0.05\right) \\
(\mathrm{cM})\end{array}$ & $\begin{array}{l}\text { Flanking markers for the } \\
\text { maximum LDLA }\end{array}$ & $\begin{array}{c}\text { Maximum } \mathrm{LRT}^{3} \\
\left(P_{g} \text {-value }\right)\end{array}$ & $\begin{array}{l}\text { Significant } \\
\text { LDLA intervals } \\
\quad(\mathrm{cM})\end{array}$ \\
\hline \multirow[t]{3}{*}{2} & 83.1 & [s47616.1-OAR2_88340779.1] & 75.1 & $83.1-83.2$ \\
\hline & 140.36 & [s25821.1-OAR2_149199138.1] & 80.20 & \\
\hline & 185.0 & {$[\mathrm{~s} 06128.1-\mathrm{s} 70629.1]$} & 79.37 & $185-185.1$ \\
\hline 3 & 94.4 & [OAR3_100129266.1-OAR3_100393157.1] & 75.64 & - \\
\hline 8 & 80.6 & s26350.1-OAR8_86871896.1] & 72.81 & - \\
\hline 11 & 56.78 & {$[\mathrm{~s} 68143.1-\mathrm{s} 02321.1]$} & 71.341 & $56.8-56.9$ \\
\hline 13 & 71.82 & [s64654.1-DU360920_246.1] & 74.307 & $68.5-71.8$ \\
\hline \multirow[t]{2}{*}{14} & 32.0 & OAR14_33291858.1-OAR14_33340378.1] & 68.88 & - \\
\hline & 43.28 & [s54719.1-OAR14_45342785.1] & 69.17 & - \\
\hline 17 & 33.8 & OOAR17_36829676.1-s46426.1] & 74.50 & - \\
\hline 22 & 23.76 & [s69443.1-DU467879_183.1] & 69.67 & - \\
\hline \multirow{2}{*}{25} & 16.58 & [s37560.1-OAR25_17161978.1] & 84.38 & $16.5-16.6$ \\
\hline & 32.5 & [OAR25_33894798.1-OAR25_33941270.1] & $\begin{array}{c}\left(P_{g} \text {-value }<0.05\right) \\
77.04\end{array}$ & $32.5-35$ \\
\hline
\end{tabular}

${ }^{1} \mathrm{OAR}=$ ovine chromosome.

${ }^{2}$ Position of the chromosome $(\mathrm{cM})$ where $5 \%$ chromosome-wise significant $\left(P_{c^{-}}\right.$value $\left.<0.05\right)$ haplotype associations were identified by LDLA.

${ }^{3} P_{g}$-value: The genome-wise $P$-value is indicated only for the haplotype associations exceeding the $5 \%$ genome-wise threshold established on the basis of the chromosome-wise significance $P$-values and considering the 26 autosomes analyzed.

${ }^{4} \mathrm{~A}$ significant LDLA interval $(\mathrm{cM})$ was defined by clustering close-by significant $\left(P_{c}\right.$-value $\left.<0.05\right)$ LDLA associations on a chromosome $($ allowing gaps no greater than $5 \mathrm{cM})$. 


\section{SCS - LDLA scan}

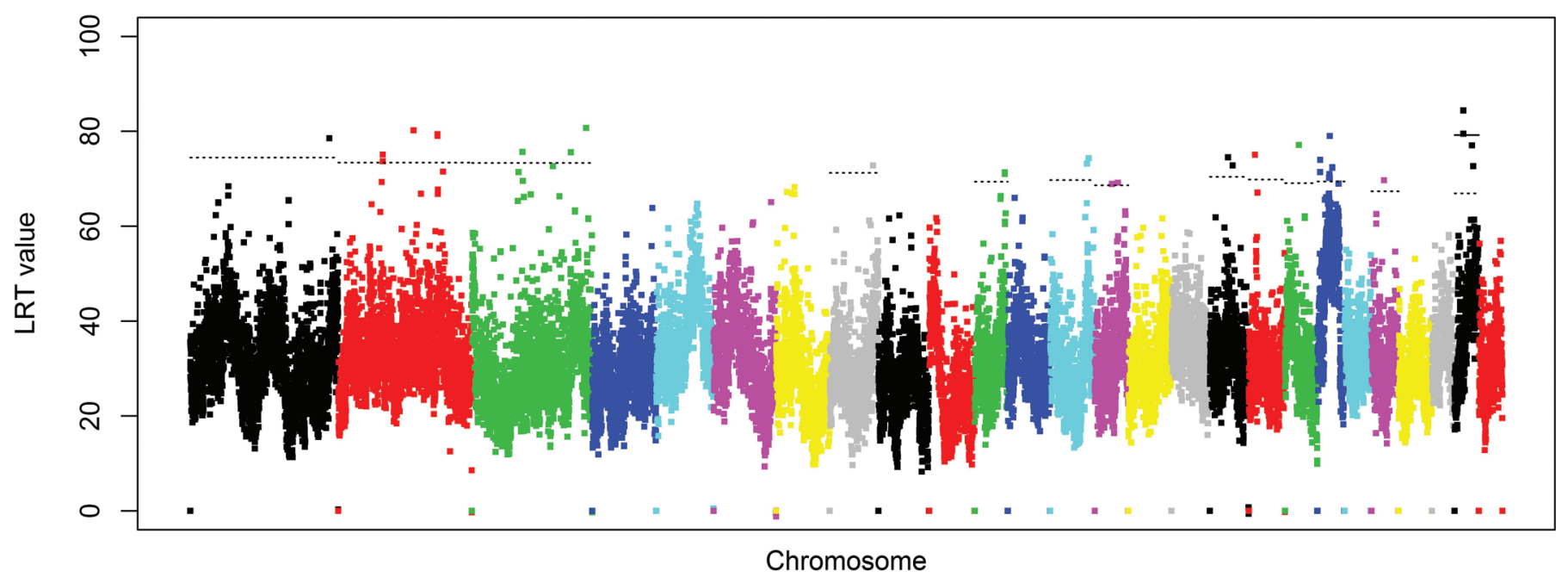

Figure 2. Results genome scan based on the combined linkage disequilibrium and linkage (LDLA) performed for the SCS trait studied in the present work. Likelihood ratio test (LRT) values obtained across the 26 ovine autosomes are represented. For the chromosomes (OAR) showing significant results, the dashed horizontal lines indicate the $5 \%$ chromosome-wise significance threshold and the solid line (on OAR25) indicates the $5 \%$ genome-wise significance threshold. Color version available online.

(Raadsma et al., 2009). Although parasite resistance traits are not directly related to mastitis resistance, we provide these correspondences (Supplemental Table S1; https://doi.org/10.3168/jds.2018-14736) considering that when a QTL for SCS overlaps with previously reported QTL for parasite resistance, this could serve as a hint to identify a gene or genes that are influencing the general immune response and that could have pleiotropic effects on disease resistance, from mastitis to parasite or other infection diseases. The region showing coincidence with the largest number of previously reported QTL for health-related traits was the LDLA significant association involving the TGI of 22 to 28 $\mathrm{Mb}$ on OAR20, although none of those coincident associations refer to mastitis resistance. Interestingly, the 22 - to $28-\mathrm{Mb}$ interval involves the major histocompatibility complex (MHC) class II region ( $D Q A$, OVAR-DRB3, HLA_DRA genes). In addition, looking in detail at studies recently reported in sheep for QTL influencing mastitis resistance related traits, we have seen that some of our significant LDLA associations were close to the reported associations although not always overlapped. For example, the significant association found on OAR19 in our study (at 26.17 Mb) is close to a large number of associations reported in Chios sheep for many different mastitis resistance traits (SCC, clinical mastitis, total viable bacterial count in milk, and so on) in the interval 26.442-28.134 Mb of that chromosome (Banos et al., 2017). Similarly, our results show vicinity to some SCC QTL reported in a commercial French dairy sheep population on OAR8
(82.60 Mb), OAR13 (70.89 Mb), OAR14 (39.40 Mb), and OAR19 (28.60 Mb; Rupp et al., 2015).

On the other hand, the TGI regions defined by our results did not show relevant overlapping with QTL influencing udder traits in sheep; only the OAR25 QTL detected by LA showed correspondence with 2 associations identified for the teat number trait (Supplemental Table S1; https://doi.org/10.3168/jds.2018-14736). As seen in Supplemental Table S2 (https://doi.org/10 .3168/jds.2018-14736), our results showed correspondence with 19 bovine QTL for mastitis-related traits, and 6 of these coincidences were found within the OAR20 QTL as defined by LDLA, which corresponds to the region 21.96 to $28.74 \mathrm{Mb}$ of bovine chromosome 23 (BTA23) where the bovine MHC is located (Supplemental Table S2). In addition, the associations reported in the present work for SCS overlapped with 21 bovine QTL previously reported for udder morphology traits. The udder traits affected by the larger number of these coincidences were teat length and udder depth, followed by teat placement and udder composite index (Supplemental Table S3; https://doi.org/10.3168/jds .2018-14736).

A total of 90 features, including 56 annotated protein-coding genes, 11 nonannotated protein-coding genes, and 1 pseudogene were identified by the Biomart extraction tool in the LA-defined TGI (Supplemental Table S4; https://doi.org/10.3168/jds.2018-14736). Within the LDLA-defined TGI, Biomart identified a total of 144 annotated protein-coding genes, 69 nonannotated protein-coding genes, and 1 pseudogene 
(Supplemental Table S5; https://doi.org/10.3168/jds .2018-14736). A total of 74 genes included in the considered immune databases were identified within the statistically significant TIG, 16 and 58 within associations identified by LA and LDLA, respectively, with 5 genes detected within TGI defined by both analyses (Supplemental Table S6; https://doi.org/10.3168/jds .2018-14736). The OAR20 LDLA QTL at 22 to $28 \mathrm{Mb}$ included the largest number of immune-related genes (47; Supplemental Table S6).

\section{A Detailed Analysis of OAR20: Selection of Segregating Trio Samples for Whole- Genome Sequencing}

The selection of the OAR20 QTL for a more detailed study based on whole-genome analysis was supported by the facts that it was the only genome-wide significant effect detected by LA and that it was also detected by LDLA. In addition, the TGI estimated for this QTL in the present study $(20.9-23.8 \mathrm{Mb})$ overlaps with the QTL flanking interval (BM1258-OLADBRPS, which approximately corresponds to the region 20 to $34 \mathrm{Mb}$ on the Oar_v3.1 reference genome) of one of the segregating families of the SCS QTL reported by Gutiérrez-Gil et al. (2007). Taking into account the 2 peaks identified in the across-family LRT profile obtained for OAR20 (Supplemental Figure S1; https://doi.org/10.3168/jds .2018-14736) and the within-family analysis results (Supplemental Figure S2, https://doi.org/10.3168/jds .2018-14736; Table 1), we selected family 1 (peak at $18.82 \mathrm{cM}$, close to the maximum across-family LRT at $21.52 \mathrm{cM}$ ) and family 6 (peak at $38.12 \mathrm{cM}$, overlapping with the secondary QTL peak identified in the acrossfamily analysis at $38 \mathrm{cM}$ ) to further explore the genetic basis of the SCS QTL identified on OAR20.

Information regarding the selection of animals for whole-genome sequencing for the 2 segregating selected families is provided in Supplemental File S1 (https:// doi.org/10.3168/jds.2018-14736). Briefly, based on the within-family phase segregating study, the daughters included in Trio 1 were 5481 (QQ, YD_SCS: -0.13 ; position $21 / 89$ in the ranked list of $Q$-daughters by the lowest phenotype values) and 4404 ( $q q$, YD_SCS: 0.259 ; position $8 / 80$ in the ranked list of $q$-daughters by the highest phenotype values), referred hereafter as QQ1_5481 and qq1_4404. The daughters included in Trio 2 were 5594 ( $Q Q$, YD_SCS: -0.342 ; position $3 / 147$ in the ranked list of daughters by the lowest phenotype values) and 4772 ( $q q$, YD_SCS: 0.4356 ; position $6 / 117$ in the ranked list of $q$-daughters by the highest phenotype values), hereafter referred to as QQ6_5594 and qq6_4772. A detailed characterization at the phe- notypic and genotypic levels for the animals selected for WGSeq analysis is provided in Table 3.

\section{Variant Survey Performed in the OAR20 QTL Region and Concordance Tests}

The whole-genome data sets showed an average number of raw reads per sample of 496,352,108 paired reads. For the 6 sequenced samples, the sequencing depth across the genome ranged between $9.89 \times$ to $19.05 \times$. In the OAR20 studied interval, the sequencing depth was very similar, ranging from $9.66 \times$ to $18.7 \times$ (average depth $15.25 \times$ ). After the Trimmomatic quality trimming, $\sim 92 \%$ of the reads were aligned against the sheep reference genome (Oar_v3.1), and $99.40 \%$ of them could be mapped. Considering the TGI of the within-family analyses for family $1(14.2-24.2 \mathrm{Mb})$ and family 6 (19.9-41.7 Mb), we performed a variant calling analysis in the OAR20 genomic interval 14.2 to $41.7 \mathrm{Mb}$. The number of variants identified across this whole genomic interval was 299,053 for Samtools and 301,954 by GATK. After applying the Snpshift filters, the number of genetic variants identified across that specific region were 279,048 with GATK and 268,568 with Samtools. A total of 227,030 variants were commonly identified by the 2 methods (so-called highquality variants) across the whole considered interval. Next, various concordance tests were performed based on the genotypes of the 6 sequenced samples.

For the 2 sequenced trios, the initial concordance tests performed considered the TGI defined based on the CI estimated in the within-family analysis for family 1 (Trio 1-fam1) and family 6 (Trio2-fam6). We termed the one of the 2 concordance tests "Trio1-fam1Region1," which examined the QTL concordance pattern in the 3 samples included in Trio 1 (Sire1_1444, QQ1_5481 and qq1_4404) across the region 14.2-24.2 $\mathrm{Mb}$ of OAR20, and the other "Trio2-fam6-Region2," which selected the concordant variants identified in the samples of Trio 2 (Sire6_2406, QQ6_5594, and qq6_4772) across the region 19.9 to $41.7 \mathrm{Mb}$ (Table 4).

From the initial list of high-quality variants identified within the defined "Region1" and "Region2" (70.541 and 195.983 variants, respectively), the total number of concordant mutations identified in each of these concordance tests was 6,968 and 40,870 genetic variants, respectively. The annotation of these variants identified 1,646 and 17,897 intragenic variants (including SNP and Indels) for "Trio1-fam1-Region1" and "Trio2-fam6Region2," respectively, resulting in 2,275 and 22,701 functional annotation variants, respectively (Supplemental Tables S7 and S8; https://doi.org/10.3168/jds .2018-14736). 


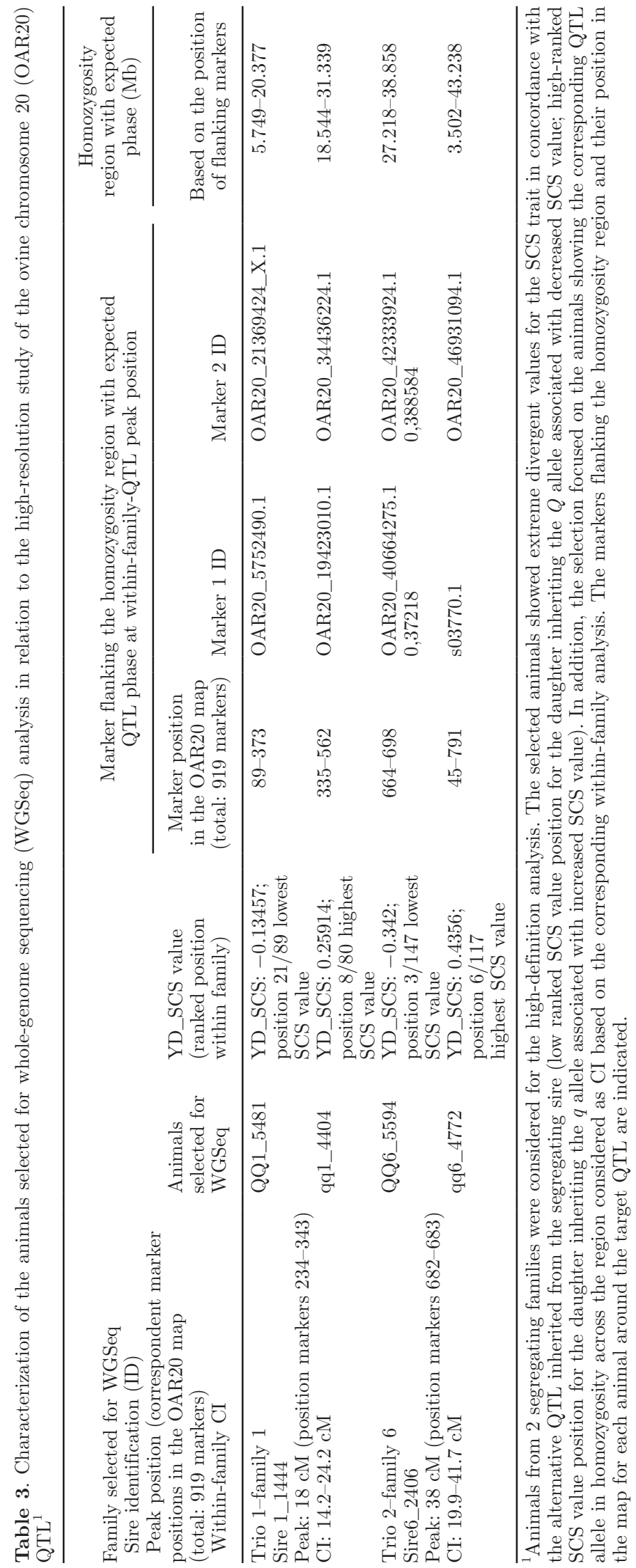


Considering the possible bias that within-family LA may introduce in the estimation of QTL position, we defined a third concordance test focused on the significant interval defined by LDLA (22-28 Mb). This interval shows a $1.8 \mathrm{Mb}$ of coincidence with the considered "Region1" and is completed included within the interval defined as "Region2." To confirm the samples that should be considered for this concordance test, we first confirmed the phase of the daughters of the 2 trios around the QTL peak based on LDLA (23.76 Mb). We observed that daughter QQ1_5481 from Trio 1 did not carry the expected chromosomal sire phase at this position (it showed the $q$ phase instead). Furthermore, daughter QQ6_5594 showed the right $Q$ phase from its sire, but its homozygous region was very short and just coincident with the LDLA peak (23.476-23.561). Within the LDLA significant interval $(22-28 \mathrm{Mb})$, the 2 susceptible daughters from both trios were homozygous for the corresponding $q$ paternal phase (see Table $3)$. Hence, the third concordance test, called "Trio1\&2Region3" considered 4 samples: the 2 segregating sires, Sire1_1444 and Sire6_2406, and the 2 susceptible daughters, qq1_4404 and qq6_4772. In this region, a total of 2,206 intragenic variants were concordant with the QTL segregation pattern and caused 2,620 annotation variants (Supplemental Table S9; https://doi.org/ 10.3168/jds.2018-14736).

From the 3 lists of concordant intragenic annotation variants (Supplemental Tables S7, S8, and S9; https:// doi.org/10.3168/jds.2018-14736), those variants classified by the eVEP software as "moderate" or "high_impact" in affecting protein function were selected for further assessment (Supplemental Table S10; https:/ /doi.org/10.3168/jds.2018-14736). For the mutations included in this list for which a gene symbol was not available from the sheep reference genome, we searched for orthologous genes in reference species (Homo sapi-

Table 4. Concordance tests performed, with a summary of the samples and region considered in the 3 concordance tests performed in the present study

\begin{tabular}{llc}
\hline Concordance test & $\begin{array}{l}\text { Samples } \\
\text { considered }\end{array}$ & $\begin{array}{c}\text { Region considered } \\
(\mathrm{Mb})\end{array}$ \\
\hline Trio1-fam1-Region1 & Sire 1_1444 & $14.2-24.2$ \\
& QQ1_5481 & \\
Trio2-fam6-Region2 & Sire6_4404 & 19.9-41.7 \\
& QQ6_5594 & \\
Trio 1\&2-Region3 & qq6_4772 & $22-28$ \\
& Sire 1_1444 & \\
& Sire6_2406 & \\
& qq1_4404 & \\
& qq6_4772 & \\
\hline
\end{tabular}

ens, Bos taurus, Mus musculus) and considered those showing the highest Query\%id parameter values, with a minimum of 60 . In the list of concordant intragenic variants of medium/high impact presented in Supplemental Table S10, we highlight those causing a deleterious mutation based on the SIFT software results (highlighted in red font) and those included within genes considered as immune-related genes (highlighted in yellow cell background) based on our reference list. Among the 12 missense concordant mutations identified from the "Trio1-fam1-Region1" concordance test, all of them were of moderate impact, 2 were deleterious (within the $P G C$ and $G U C A 1 B$ genes), and 2 were within immune-related genes, $M D F I$ and $C C N D 3$ (Supplemental Table S10). For the concordance test "Trio2fam6-Region2," apart from 2 high-impact variants (1 stop_gained, 1 frameshift_variant) identified within olfactory receptor genes (ENSOARG00000009186 and ENSOARG00000017255), 191 missense variants of moderate impact were present, 38 of which were classified as deleterious. Among the 73 genes carrying missense mutations in this region, we found 16 genes related to the immune system, especially related to the MHC, directly or through their corresponding orthologous genes [AGER, BTN1A1, BTNL2, JARID2, MOG, NOTCH4, PKHD1, PLA2G7, ENSOARG00000015646 (HLA-DRB1; H. sapiens), ENSOARG00000015707 (HLA-DQA1; H. sapiens), ENSOARG00000001254 (TNXB; B. taurus), ENSOARG00000009395 (HLA$C ; \quad H$. sapiens), ENSOARG00000009868 (MIC1; B. taurus), ENSOARG00000010572 (BoLA; B. taurus), ENSOARG00000015002 (HLA-B; H. sapiens), ENSOARG00000018075 (BoLA; B. taurus)]. From the deleterious mutations identified within this region, 10 were within some of the immune-linked genes previously mentioned: PKHD1, NOTCH4, AGER, MOG, and annotated genes orthologous to the human $H L A-A$ and $H L A-B$ and bovine BoLA genes (see Table 5 ).

Among the concordant variants identified based on the concordance test "Trio1\&2-Region3," 2 stop_gained variants were localized in the novel gene ENSOARG0000001542\%, which has no orthologous genes in other genomes (Supplemental Table S10), and 61 missense variants, 16 of which were included in immune-related genes (CDSN, GNL1, MDC1, PKHD1, RHAG, MIC1, and TNXB; Supplemental Table S10). Four of the missense variants within region 3 were classified as deleterious, 2 of them in the immunerelated PKHD1 gene (rs404196749 and rs412600919), 1 in ENSOARG00000010006 (orthologous to the bovine POU5F1 gene), and 1 in the novel gene $E N$ SOARG0000001542\%. 


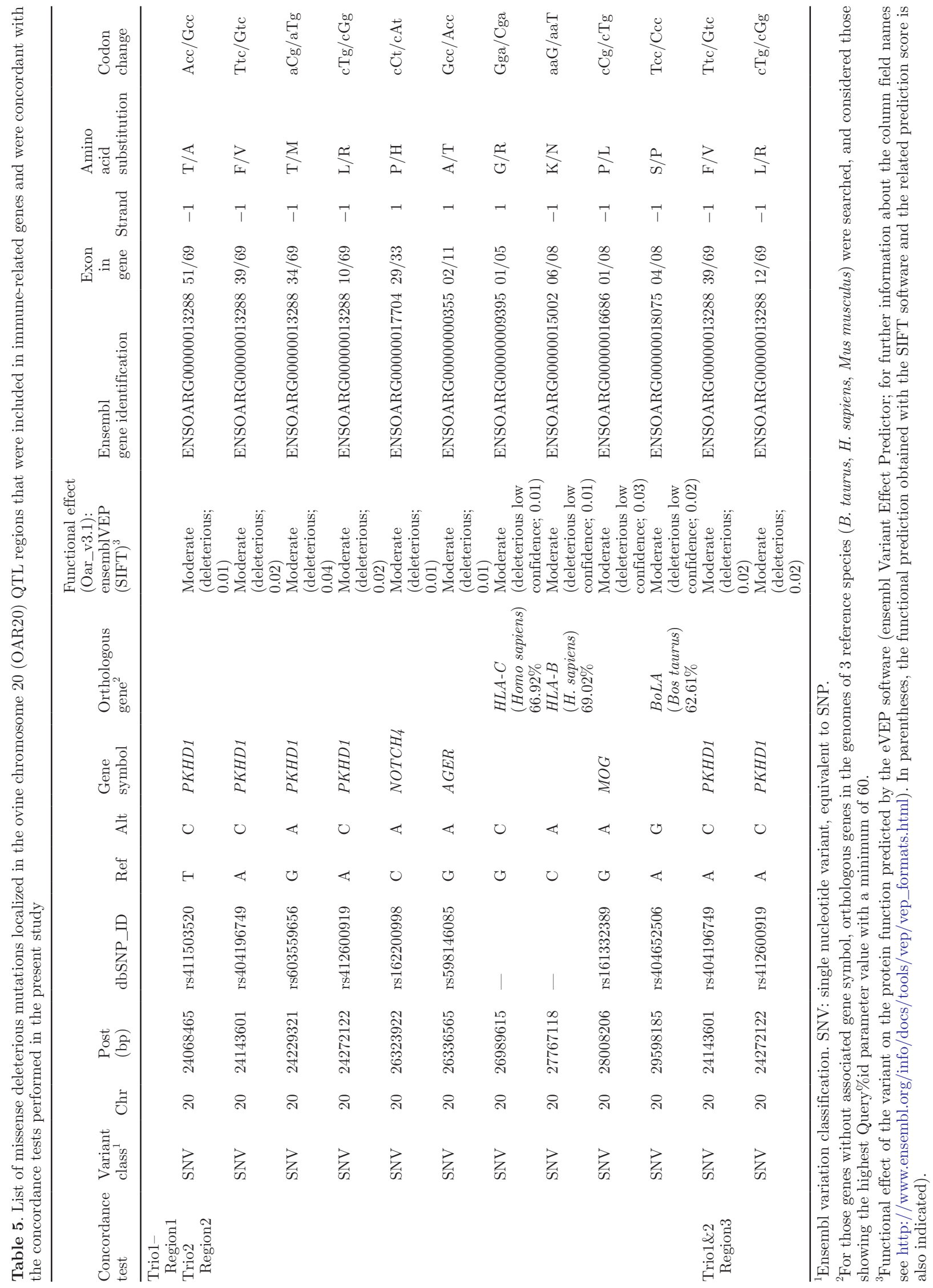




\section{DISCUSSION}

The present study mapped QTL underlying SCS, a classical indicator trait of mastitis resistance, in Spanish Churra dairy sheep. The most significant QTL, detected at the genome-wide level by LA (20.9-23.8 $\mathrm{Mb})$, and confirmed by LDLA (22-28 Mb), was located on OAR20. This QTL was previously identified through a low-density microsatellite-based genome scan in a different commercial population of Churra sheep (Gutiérrez-Gil et al., 2007). Hence, the present study has replicated for this breed the presence of a QTL for mastitis resistance on OAR20. Whereas the initial scan presented by Gutiérrez-Gil et al. (2007) only identified the OAR20 QTL effect in the present study by using a different population and benefitting from increased marker accuracy, we identified 2 additional QTL at the chromosome-wide level by LA, on OAR5 and OAR25, together with 22 significant associations identified by LDLA, 2 of them replicating the LA-detected effects on OAR20 and OAR25. In addition to the classical LA analysis method, which is appropriate for the half-sib population analyzed here, the LDLA approach can be used to complete the global picture of segregating effects because the effects captured by these 2 analysis methods pinpoint associations with different features. For example, whereas in our design LA will only detect QTL if several sires are heterozygous at the same QTL $(Q q)$, many marker trait associations that do not satisfy this assumption but have a genuine association at the population level can be detected by LDLA. This explains the larger number of significant associations identified by LDLA (22) than by LA (3) in the present study, similar to previous studies performed in the same commercial population regarding milk production or parasite resistance traits (Garcia-Gámez et al., 2013; Atlija et al., 2016). In any case, the within-family information provided by LA in a half-sib population like the one studied here is of major value to select the families that should be considered from the global population in further fine-mapping, high-resolution studies aiming at the identification of the causal mutation. Hence, the selection of trios for WGSeq presented in this work relies completely on the within-family information provided by the LA genome scan summarized in Table 1.

When examining the correspondence between the TGI defined by our analyses and QTL previously described in sheep (Supplemental Table S1; https://doi .org/10.3168/jds.2018-14736), several coincidences with general health traits are apparent, although only in one case (in relation to the OAR22 QTL) does the previously reported effect influence the SCS trait (Raadsma et al., 2009). Interestingly, we did not find any QTL in the region of the SOCS2 gene (OAR3: 129,720,516-
129,722,508 according Oar_v3.1), where a causal mutation for mastitis resistance has been reported in a French dairy sheep population (Rupp et al., 2015). A specific evaluation of the SOCS2_p.R96C mutation in the males of the Churra population studied in the present work showed that all of them where homozygous for the $\mathrm{C}$ base present in the reference sequence, and none of them were carriers of the $\mathrm{T}$ allele observed in susceptible animals in the French population.

Apart from the initial description in Churra sheep, no other study has reported a marker association with sheep mastitis resistance in the region suggested to harbor the OAR20 QTL by LA and LDLA (20.9-28 $\mathrm{Mb}$ ), although this region does harbor QTL for other health-related traits (IgA level, Haemonchus contortus FEC, Maedi-Visna virus, ovine pulmonary adenocarcinoma, Salmonella abortus ovis susceptibilities). The low number of correspondences observed between the significant associations reported here with ovine QTL for udder traits may be explained by the limited number of QTL mapping studies on this species. Nevertheless, although our systematic search with the Search tool of SheepQTLdb did not report a direct overlapping with the QTL reported for udder morphology in Churra sheep (Gutiérrez-Gil et al., 2008), it should be taken into account that the flanking intervals of 2 QTL for udder depth reported in this breed would be close to the LDLA significant associations reported here on OAR14 and OAR20 (SheepQTLdb QTL ID: 13658 and 13660, respectively; flanking intervals: $53.5-60.2 \mathrm{Mb}$ and $7.2 \mathrm{Mb}$, respectively).

The correspondence of the OAR20 QTL with several cattle QTL related to mastitis resistance described in the genomic region including the bovine MHC suggests that some genetic mechanisms controlling mastitis resistance might be shared between cattle and sheep. Several studies support the associations between MHC polymorphisms, especially in the BoLA-DRB3.2 gene, on mastitis resistance in cattle (reviewed by Behl et al., 2012), whereas in sheep, few studies have focused on this potential relationship. Hereafter, the most important results from the initial QTL mapping analysis presented here are (1) the replication of the OAR20 QTL by using a medium density SNP chip and 2 different analysis approaches, LA and LDLA, and (2) the identification of a list of functional candidate genes related to immune traits included within the CI defined for the significant QTL identified by LA and LDLA (Supplemental Table S6; https://doi.org/10 .3168/jds.2018-14736). Polymorphisms affecting these genes should be assessed as potential genetic markers in relation to increased SCS in dairy sheep. Comparing with results reported in goats, we did not find a relevant coincidence, as the sheep genomic regions on 
OAR11 orthologous to the intervals harboring recently reported QTL on goat chromosome 19 for SCS and udder traits (Martin et al., 2018; Mucha et al., 2018; 26-28 Mb and 40-42 Mb) are not coincident with the significant LDLA association reported here on OAR11 (56.8-56.9 Mb). The scarce number of goat studies on this topic may explain the lack of coincidences. In addition, the correspondence of the sheep associations here detected for SCS with QTL/associations reported in cattle for udder traits, especially for teat length and udder depth, support the phenotypic and genetic correlations estimated between SCS and udder traits and the use of indirect selection based on udder traits to improve global mammary gland health in sheep.

In the second section of our study, we used nextgeneration sequencing to obtain a deeper insight into the OAR20 QTL region. Genome-wide association studies based on sequence data have shown high power to identify putative causative variants and stronger signals of association (Daetwyler et al., 2014; Höglund et al., 2014; Sahana et al., 2014). Both the LA and LDLA statistical profiles showed indications of more than one QTL peak, although they both showed the maximum significant values in close positions (21.52 and $23.52 \mathrm{cM}$ for LA and LDLA, respectively). Because the sequencing analysis is based on segregating trios, we focused the analysis of genetic variability within the specific CI estimated for the 2 families showing the highest support for the OAR20 QTL, family 1 and family 6 , although because the statistical profile of family 6 suggests that this family could be segregating for more than one QTL, we screened 2 different and partially overlapping regions of the chromosome (14.2-24.2 Mb and 19.9-41.7 $\mathrm{Mb}$ ). The within-family discrepancies regarding the QTL peak position show a complex case of gene fine-mapping and the importance of performing a detailed study of the phase status in the considered animals. Based on our study of the phase status, we determined that the significant interval highlighted by the LDLA analysis could only be considered for a concordance test involving the 2 segregating sires and the 2 susceptible daughters, qq1_4404 and qq6_4472. Hence, considering the difficulties of leading with segregating families showing discrepancies in LA-estimated CI, we considered it appropriate to run the 3 described different concordance tests to filter the genetic variability identified across the considered intervals.

Within the 3 different intervals considered in these concordance tests and after applying the genotype concordance filtering considering the QTL segregation pattern, we focused on the genes that harbored intragenic variability and that showed functional effects on the encoded protein function, mainly missense variants. We acknowledge that noncoding or intergenic regions were not considered in the later steps of assessment of potential causal mutations. Although different studies have shown that noncoding variants may directly affect gene expression and protein abundance (Zappala and Montgomery, 2016; Igartua et al., 2017), and therefore represent impactful variation, we considered that focusing on the coding region was an appropriate initial approach to evaluate the high density variability study performed on this work. Among the genes harboring the potential functional relevant variants, we highlighted those related to immunity based on our reference candidate gene list (Supplemental Table S10, https://doi.org/10.3168/jds.2018-14736; a total of 85 variants highlighted in yellow). We recognize that any of these 85 missense variants concordant with the QTL segregation pattern (considering the 3 tests) and within a list of 23 immune-related genes (CCND3, $M D F I$, PLA2G7, PKHD1, HLA-DRB1, HLA-DQA1, DQA, BTNL2, NOTCH4, AGER, TNXB, HLA-C, HLA-B, MIC1, CDSN, BoLA, MDC1, MOG, BTN1A1, JARID2, RHAG, MIC1, and GNL1) could be considered as candidate variants to explain the studied OAR20 QTL effect. Among the 23 harboring genes of these mutations, obvious candidates are included in the ovine MHC (HLA-DRB1, HLA-DQA1, DQA, HLa-B, HLA$C$, and $B o L A-H L A-A)$. In cattle, bovine lymphocyte antigen (BoLA) has been associated with resistance to mastitis (Mallard et al., 1995; Rupp et al., 2007) and SCC (Sharif et al., 1998; Chu et al., 2012), with several studies supporting the direct association of these traits with the DRB3 locus. In addition, in Holstein cattle, heterozygosity of the $B o L A-D Q A 1$ gene has been associated with resistance to mastitis progression (Takeshima et al., 2008). The search for associations between the remaining filtered candidate genes and mastitis did not yield any notable results.

In an attempt to obtain further information from the functional annotation analysis, the list of 85 missense QTL concordant mutations within immune-related genes was further filtered to extract those mutations showing deleterious effects on protein function. We consider that among the listed variants, priority should be given to the 10 concordant variants identified through concordance test "Trio2-family6-Region2," which are distributed across 7 different genes [PKHD1, NOTCH4, AGER, ENSOARG00000009395 (HLA-C, H. sapiens), ENSOARG00000015002 (HLA-B, H. sapiens), MOG, and ENSOARG00000018075 (BoLA, B. taurus, orthologous to human $H L A-A)$ ]. Two of these mutations, located on PKHD1, were also concordant with the concordance test "Trio1\&2-Region3" (Table 5). However, the known biological function of the PKHD1 gene, which encodes for the fibrocystin protein involved in the polycystic kidney and hepatic disease-1, and the lack of significant 
expression of this gene in the mammary gland (Menezes et al., 2004) excluded this gene as a relevant candidate for our study. To confirm the expression of the remaining immune genes harboring deleterious variants in the sheep mammary gland, we estimated their expression levels from RNA-Seq data previously analyzed by our research group to study the dynamic transcriptome (at 4 time points, i.e., d 10, 50, 120, and 150 after lambing) of the sheep mammary gland (Suárez-Vega et al., 2015; see Supplemental Table S11; https://doi .org/10.3168/jds.2018-14736). This data set confirmed that, among the 7 considered genes, $\mathrm{NOTCH}_{4}$ showed an average low level of gene expression (1.964 FPKM) across the studied time points and samples. In contrast, ENSOARG00000009395 and ENSOARG00000015002 (orthologous to the human $H L A-C$ and $H L A-B$ genes, respectively) showed moderate gene expression levels (46.914 and 389.569 average FPKM values, respectively). $H L A-B$ showed the greatest variation, from 79.685 to 2017.630 FPKM Supplemental Table S11).

The $\mathrm{NOTCH}_{4}$ gene encodes a member of the NOTCH family of proteins, which are transmembrane receptors that interact with membrane-bound ligands encoded by the Delta/Serrate/Jagged gene families. The Notch signaling pathway is an evolutionarily conserved intercellular signaling mechanism (reviewed by Callahan and Egan, 2004). A role of this protein has been suggested in relation to mammary gland development and mammary tumorigenesis, but no previous reports are available in relation to inflammation of the mammary gland. Regarding the proteins encoded by the $H L A-B$ and $H L A-C$ genes, these are class I MHC molecules whose function is to display peptide fragments of non-self-proteins from within the cell to cytotoxic $\mathrm{T}$ cells. The proteins encoded by these genes have been related to many disease traits, primarily with regard to autoimmune diseases and also with regard to human immunodeficiency virus (HIV) control or increased risk of developing Crohn's disease (Colmegna et al., 2004; Vince et al., 2016).

\section{CONCLUSIONS}

This gene mapping study for SCS in dairy sheep replicated a previously reported QTL for this trait on OAR20. Additionally, the use of a medium-high SNP chip and 2 complementary analytical approaches (LA and LDLA) allowed the identification of other genomic regions that might be related to ewe susceptibility to subclinical mastitis. For all of these regions, we present a list of positional and functional candidate genes that should be evaluated by future studies. In addition, for the replicated OAR20 QTL, we exploited the whole-genome sequencing of segregating trios to fully characterize the putative harboring genomic region. By performing high-resolution analyses and consecutive filtering strategies, the study provides a list of promising candidate genes and genetic variants that underlie the targeted QTL effect. Future studies should address the genotyping of the suggested variants in commercial populations and evaluate their associations with indicator traits of udder inflammation (SCS, clinical mastitis). Functional characterization experiments should then be designed to understand the biological mechanism controlling a fraction of the genetic variation that controls the complex trait of resistance to mastitis in sheep.

\section{ACKNOWLEDGMENTS}

This research work was partially funded by the 3SR (Sustainable Solutions for Small Ruminants) project funded by the European Commission within the FP7 Programme (FP7-KBBE245140) and by the AGL201566035-R project, funded by the Spanish Ministry of Economy and Competitiveness (MINECO, Madrid, Spain) and co-funded by the European Regional Development Fund. We thank the National Association of Spanish Churra Breeders (ANCHE) for the close collaboration with our research group and the support for generating sequencing data of Churra genomes. B. Gutiérrez-Gil is funded through the Spanish "Ramón y Cajal" Programme (RYC-2012-10230) from MINECO. The support and availability to the computing facilities of the Foundation of Supercomputing Center of Castile and León (FCSCL, León, Spain; http://www.fcsc.es) are greatly acknowledged. C. Esteban-Blanco is funded by an FPU contract from MINECO (Ref. BES-201607-8080).

\section{REFERENCES}

Anderson, C. A., F. H. Pettersson, G. M. Clarke, L. R. Cardon, A. P. Morris, and K. T. Zondervan. 2010. Data quality control in genetic case-control association studies. Nat. Protoc. 5:1564-1573. https:/ /doi.org/10.1038/nprot.2010.116.

Arranz, J. J., and B. Gutiérrez-Gil. 2012. Detection of QTL Underlying Milk Traits in Sheep: An Update. N. Chaiyab, ed. InTech, New York, NY.

Atlija, M., J.-J. Arranz, M. Martinez-Valladares, and B. GutiérrezGil. 2016. Detection and replication of QTL underlying resistance to gastrointestinal nematodes in adult sheep using the ovine $50 \mathrm{~K}$ SNP array. Genet. Sel. Evol. 48:4. https://doi.org/10.1186/s12711 -016-0182-4.

Banos, G., G. Bramis, S. J. Bush, E. L. Clark, M. E. B. McCulloch, J Smith, G. Schulze, G. Arsenos, D. A. Hume, and A. Psifidi. 2017. The genomic architecture of mastitis resistance in dairy sheep. BMC Genomics 18:624. https://doi.org/10.1186/s12864-017-3982 -1 .

Barillet, F., J. M. Astruc, and G. Lagriffoul. 2006. Taking into account functional traits in dairy sheep breeding programs through the French example. Vol 121, pages 57-64 in Proceeding of the EAAP. Wageningen, NLD. Academic Publishers., Kuopio, Finland. 
Behl, J. D., N. K. Verma, N. Tyagi, P. Mishra, R. Behl, and B. K. Joshi. 2012. The major histocompatibility complex in bovines: A review. ISRN Vet. Sci. 2012:872710. https://doi.org/10.5402/ $2012 / 872710$

Bolger, A. M., M. Lohse, and B. Usadel. 2014. Trimmomatic: A flexible trimmer for Illumina sequence data. Bioinformatics 30:21142120. https://doi.org/10.1093/bioinformatics/btu170.

Broad Institute. 2017. Picard Tool, Version 1.128. Accessed Dec. 15, 2017. http://broadinstitute.github.io/picard/.

Broman, K., and S. Sen. 2009. A Guide to QTL Mapping with R. Springer, New York, NY.

Callahan, R., and S. E. Egan. 2004. Notch signaling in mammary development and oncogenesis. J. Mammary Gland Biol. Neoplasia 9:145-163. https://doi.org/10.1023/B:JOMG.0000037159.63644 .81 .

Casu, S., S. Sechi, S. L. Salaris, and A. Carta. 2010. Phenotypic and genetic relationships between udder morphology and udder health in dairy ewes. Small Rumin. Res. 88:77-83. https://doi.org/10 .1016/J.SMALLRUMRES.2009.12.013.

Chu, M. X., S. C. Ye, L. Qiao, J. X. Wang, T. Feng, D. W. Huang, G. L. Cao, R. Di, L. Fang, and G. H. Chen. 2012. Polymorphism of exon 2 of BoLA-DRB3 gene and its relationship with somatic cell score in Beijing Holstein cows. Mol. Biol. Rep. 39:2909-2914. https://doi.org/10.1007/s11033-011-1052-3.

Cingolani, P., V. M. Patel, M. Coon, T. Nguyen, S. J. Land, D. M. Ruden, and X. Lu. 2012. Using Drosophila melanogaster as a model for genotoxic chemical mutational studies with a new program, SnpSift. Front. Genet. 3:35. https://doi.org/10.3389/fgene.2012 .00035 .

Colmegna, I., R. Cuchacovich, and L. R. Espinoza. 2004. HLA-B27associated reactive arthritis: Pathogenetic and clinical considerations. Clin. Microbiol. Rev. 17:348-369. https://doi.org/10.1128/ CMR.17.2.348-369.2004

Daetwyler, H. D., A. Capitan, H. Pausch, P. Stothard, R. van Binsbergen, R. F. Brøndum, X. Liao, A. Djari, S. C. Rodriguez, C. Grohs, D. Esquerré, O. Bouchez, M.-N. Rossignol, C. Klopp, D. Rocha, S. Fritz, A. Eggen, P. J. Bowman, D. Coote, A. J. Chamberlain, C. Anderson, C. P. VanTassell, I. Hulsegge, M. E. Goddard, B. Guldbrandtsen, M. S. Lund, R. F. Veerkamp, D. A. Boichard, R. Fries, and B. J. Hayes. 2014. Whole-genome sequencing of 234 bulls facilitates mapping of monogenic and complex traits in cattle. Nat. Genet. 46:858-865. https://doi.org/10.1038/ng.3034.

de la Fuente, L. F., G. Fernandez, and F. San Primitivo. 1996. A linear evaluation system for udder traits of dairy ewes. Livest. Prod. Sci. 45:171-178. https://doi.org/10.1016/0301-6226(96)00003-6.

Fernández, G., J. A. Baro, L. F. de la Fuente, and F. San Primitivo. 1997. Genetic parameters for linear udder traits of dairy ewes. J. Dairy Sci. 80:601-605. https://doi.org/10.3168/jds.S0022 -0302(97)75976-9.

Filangi, O., C. Moreno, H. Gilbert, A. Legarra, P. Le-Roy, and J. M. Elsen. 2010. QTLMap, a software for QTL detection in outbreed populations. Pages 1-3 in 9th World Congress on Genetics Applied to Livestock Production, Leipzig, Germany. Leipzig Gesellschaft für Tierzuchtwissenschaften 2010. Leipzig, Germany.

García-Gámez, E., B. Gutiérrez-Gil, G. Sahana, J.-P. Sánchez, Y. Bayón, and J.-J. Arranz. 2012. GWA Analysis for milk production traits in dairy sheep and genetic support for a QTN influencing milk protein percentage in the LALBA gene. PLoS One 7:e47782.

Garcia-Gámez, E., B. Gutiérrez-Gil, A. Suarez-Vega, L. F. de la Fuente, and J. J. Arranz. 2013. Identification of quantitative trait loci underlying milk traits in Spanish dairy sheep using linkage plus combined linkage disequilibrium and linkage analysis approaches. J. Dairy Sci. 96:6059-6069. https://doi.org/10.3168/jds .2013-6824.

Gonzalo, C., and V. R. Gaudioso. 1985. Evolution des types cellulaires du lait de brebis (race Churra) en fonction des dénombrements cellulaires totaux pendant la traite mécanique et manuelle. Ann. Zootech. 34:257-264.

Govignon-Gion, A., R. Dassonneville, G. Baloche, and V. Ducrocq. 2016. Multiple trait genetic evaluation of clinical mastitis in three dairy cattle breeds. Animal 10:558-565. https://doi.org/10.1017/ S1751731115002529.

Gutiérrez-Gil, B., M. F. El-Zarei, L. Alvarez, Y. Bayón, L. F. de la Fuente, F. San Primitivo, and J. J. Arranz. 2008. Quantitative trait loci underlying udder morphology traits in dairy sheep. J. Dairy Sci. 91:3672-3681. https://doi.org/10.3168/jds.2008-1111.

Gutiérrez-Gil, B., M. F. El-Zarei, Y. Bayón, L. Alvarez, L. F. de la Fuente, F. San Primitivo, and J. J. Arranz. 2007. Short communication: Detection of quantitative trait loci influencing somatic cell score in Spanish Churra sheep. J. Dairy Sci. 90:422-426.

Gutiérrez-Gil, B., C. Esteban-Blanco, P. Wiener, P. K. Chitneedi, A. Suarez-Vega, and J.-J. Arranz. 2017. High-resolution analysis of selection sweeps identified between fine-wool Merino and coarsewool Churra sheep breeds. Genet. Sel. Evol. 49:81. https://doi .org/10.1186/s12711-017-0354-x.

Höglund, J. K., G. Sahana, R. Brøndum, B. Guldbrandtsen, B. Buitenhuis, and M. S. Lund. 2014. Fine mapping QTL for female fertility on BTA04 and BTA13 in dairy cattle using HD SNP and sequence data. BMC Genomics 15:790. https://doi.org/10.1186/ 1471-2164-15-790.

Hu, Z.-L., C. A. Park, X.-L. Wu, and J. M. Reecy. 2013. Animal QTLdb: An improved database tool for livestock animal QTL/association data dissemination in the post-genome era. Nucleic Acids Res. 41:D871-D879. https://doi.org/10.1093/nar/gks1150.

Igartua, C., S. V. Mozaffari, D. L. Nicolae, and C. Ober. 2017. Rare non-coding variants are associated with plasma lipid traits in a founder population. Sci. Rep. 7:16415. https://doi.org/10.1038/ s41598-017-16550-8.

Jamrozik, J., A. Koeck, F. Miglior, G. J. Kistemaker, F. S. Schenkel, D. F. Kelton, and B. J. Van Doormaal. 2013. Genetic and genomic evaluation of mastitis resistance in Canada. Interbull Bull. 0:43-51.

Kelley, J., B. de Bono, and J. Trowsdale. 2005. IRIS: A database surveying known human immune system genes. Genomics 85:503-511. https://doi.org/10.1016/j.ygeno.2005.01.009.

Lander, E. S., and D. Botstein. 1989. Mapping mendelian factors underlying quantitative traits using RFLP linkage maps. Genetics 121:185-199.

Le Roy, P., J. M. Elsen, H. Gilbert, C. Moreno, A. Legarra, and O. Filangi. 2013. QTLMap 0.9.6 User's guide 1-56. Accessed Nov. 21, 2016. https://forge-dga.jouy.inra.fr/attachments/download/2502/ qtlmapV0.9.6.pdf.

Legarra, A., and E. Ugarte. 2005. Genetic parameters of udder traits, somatic cell score, and milk yield in Latxa sheep. J. Dairy Sci. 88:2238-2245. https://doi.org/10.3168/jds.S0022-0302(05)72899 $-\mathrm{X}$.

Li, H. 2011. A statistical framework for SNP calling, mutation discovery, association mapping and population genetical parameter estimation from sequencing data. Bioinformatics 27:2987-2993. https: //doi.org/10.1093/bioinformatics/btr509.

Li, H., and R. Durbin. 2009. Fast and accurate short read alignment with Burrows-Wheeler transform. Bioinformatics 25:1754-1760. https://doi.org/10.1093/bioinformatics/btp324.

Li, H., B. Handsaker, A. Wysoker, T. Fennell, J. Ruan, N. Homer, G. Marth, G. Abecasis, and R. Durbin. 2009. The Sequence Alignment/Map format and SAMtools. Bioinformatics 25:2078-2079. https://doi.org/10.1093/bioinformatics/btp352.

Mallard, B. A., K. E. Leslie, J. C. M. Dekkers, R. Hedge, M. Bauman, and M. J. Stear. 1995. Differences in bovine lymphocyte antigen associations between immune responsiveness and risk of disease following intramammary infection with Staphylococcus aureus. J. Dairy Sci. 78:1937-1944. https://doi.org/10.3168/jds.S0022 -0302(95)76819-9.

Martin, P., I. Palhière, C. Maroteau, V. Clément, I. David, G. T. Klopp, and R. Rupp. 2018. Genome-wide association mapping for type and mammary health traits in French dairy goats identifies a pleiotropic region on chromosome 19 in the Saanen breed. J. Dairy Sci. https://doi.org/10.3168/jds.2017-13625.

McLaren, W., B. Pritchard, D. Rios, Y. Chen, P. Flicek, and F. Cunningham. 2010. Deriving the consequences of genomic variants 
with the Ensembl API and SNP effect predictor. Bioinformatics 26:2069-2070. https://doi.org/10.1093/bioinformatics/btq330.

Menezes, L. F. C., Y. Cai, Y. Nagasawa, A. M. G. Silva, M. L. Watkins, A. M. Da Silva, S. Somlo, L. M. Guay-Woodford, G. G. Germino, and L. F. Onuchic. 2004. Polyductin, the PKHD1 gene product, comprises isoforms expressed in plasma membrane, primary cilium, and cytoplasm. Kidney Int. 66:1345-1355. https:// doi.org/10.1111/j.1523-1755.2004.00844.x.

Miglior, F., B. L. Muir, and B. J. Van Doormaal. 2005. Selection indices in Holstein cattle of various countries. J. Dairy Sci. 88:12551263. https://doi.org/10.3168/jds.S0022-0302(05)72792-2.

Mucha, S., R. Mrode, M. Coffey, M. Kizilaslan, S. Desire, and J. Conington. 2018. Genome-wide association study of conformation and milk yield in mixed-breed dairy goats. J. Dairy Sci. 101:2213-2225. https://doi.org/10.3168/jds.2017-12919.

Narasimhan, V., P. Danecek, A. Scally, Y. Xue, C. Tyler-Smith, and R. Durbin. 2016. BCFtools/RoH: A hidden Markov model approach for detecting autozygosity from next-generation sequencing data. Bioinformatics 32:1749-1751. https://doi.org/10.1093/ bioinformatics/btw044.

Østerås, O., H. Solbu, A. O. Refsdal, T. Roalkvam, O. Filseth, and A. Minsaas. 2007. Results and evaluation of thirty years of health recordings in the Norwegian dairy cattle population. J. Dairy Sci. 90:4483-4497. https://doi.org/10.3168/jds.2007-0030.

Othmane, M. H., L. F. De La Fuente, J. A. Carriedo, and F. San Primitivo. 2002. Heritability and genetic correlations of test day milk yield and composition, individual laboratory cheese yield, and somatic cell count for dairy ewes. J. Dairy Sci. 85:2692-2698. https://doi.org/10.3168/jds.S0022-0302(02)74355-5.

Raadsma, H. W., E. Jonas, D. McGill, M. Hobbs, M. K. Lam, and P. C. Thomson. 2009. Mapping quantitative trait loci (QTL) in sheep. II. Meta-assembly and identification of novel QTL for milk production traits in sheep. Genet. Sel. Evol. 41:45. https://doi .org/10.1186/1297-9686-41-45.

Raynal-Ljutovac, K., A. Pirisi, R. de Crémoux, and C. Gonzalo. 2007. Somatic cells of goat and sheep milk: Analytical, sanitary, productive and technological aspects. Small Rumin. Res. 68:126-144. https://doi.org/10.1016/j.smallrumres.2006.09.012.

Rupp, R., A. Hernandez, and B. A. Mallard. 2007. Association of bovine leukocyte antigen (BoLA) DRB3.2 with Immune response, mastitis, and production and type traits in Canadian Holsteins. J. Dairy Sci. 90:1029-1038. https://doi.org/10.3168/jds.S0022 -0302(07)71589-8.

Rupp, R., G. Lagriffoul, J. M. Astruc, and F. Barillet. 2003. Genetic parameters for milk somatic cell scores and relationships with production traits in French Lacaune dairy sheep. J. Dairy Sci. 86:1476-1481. https://doi.org/10.3168/jds.S0022-0302(03)73732 $-1$.
Rupp, R., P. Senin, J. Sarry, C. Allain, C. Tasca, L. Ligat, D. Portes, F. Woloszyn, O. Bouchez, G. Tabouret, M. Lebastard, C. Caubet, G. Foucras, and G. Tosser-Klopp. 2015. A point mutation in suppressor of cytokine signalling 2 (Socs2) increases the susceptibility to inflammation of the mammary gland while associated with higher body weight and size and higher milk production in a sheep model. PLoS Genet. 11:e1005629. https://doi.org/10.1371/journal .pgen.1005629.

Sahana, G., B. Guldbrandtsen, B. Thomsen, L.-E. Holm, F. Panitz, R. F. Brøndum, C. Bendixen, and M. S. Lund. 2014. Genomewide association study using high-density single nucleotide polymorphism arrays and whole-genome sequences for clinical mastitis traits in dairy cattle. J. Dairy Sci. 97:7258-7275. https://doi.org/ $10.3168 /$ jds.2014-8141.

Sellner, E. M., J. W. Kim, M. C. McClure, K. H. Taylor, R. D. Schnabel, and J. F. Taylor. 2007. Board-invited review: Applications of genomic information in livestock. J. Anim. Sci. 85:3148-3158. https://doi.org/10.2527/jas.2007-0291.

Sharif, S., B. A. Mallard, B. N. Wilkie, J. M. Sargeant, H. M. Scott, J. C. Dekkers, and K. E. Leslie. 1998. Associations of the bovine major histocompatibility complex DRB3 (BoLA-DRB3) alleles with occurrence of disease and milk somatic cell score in Canadian dairy cattle. Anim. Genet. 29:185-193.

Shook, G. E., and M. M. Schutz. 1994. Selection on somatic cell score to improve resistance to mastitis in the United States. J. Dairy Sci. 77:648-658. https://doi.org/10.3168/jds.S0022-0302(94)76995-2.

Suárez-Vega, A., B. Gutiérrez-Gil, C. Klopp, C. Robert-Granie, G. Tosser-Klopp, and J. J. Arranz. 2015. Characterization and Comparative analysis of the milk transcriptome in two dairy sheep breeds using RNA sequencing. Sci. Rep. 5:18399. https://doi.org/ $10.1038 /$ srep18399.

Takeshima, S., Y. Matsumoto, J. Chen, T. Yoshida, H. Mukoyama, and Y. Aida. 2008. Evidence for cattle major histocompatibility complex (BoLA) class II DQA1 gene heterozygote advantage against clinical mastitis caused by Streptococci and Escherichia species. Tissue Antigens 72:525-531. https://doi.org/10.1111/j .1399-0039.2008.01140.x.

Vince, N., H. Li, V. Ramsuran, V. Naranbhai, F.-M. Duh, B. P. Fairfax, B. Saleh, J. C. Knight, S. K. Anderson, and M. Carrington. 2016. HLA-C level is regulated by a polymorphic Oct1 binding site in the HLA-C promoter region. Am. J. Hum. Genet. 99:1353-1358. https://doi.org/10.1016/j.ajhg.2016.09.023.

Zappala, Z., and S. B. Montgomery. 2016. Non-coding loss-of-function variation in human genomes. Hum. Hered. 81:78-87. https://doi .org/10.1159/000447453. 